\title{
Densitas dan Jenis Pakan Burung Rangkong (Rhyticeros cassidix) di Cagar Alam Tangkoko Batuangus
}

\author{
Brayen Mangangantunga*, Deidy. Y. Katilia, Saroyoa, Pience V. Maabuata \\ aJurusan Biologi, FMIPA, Unsrat, Manado
}

\begin{tabular}{l}
\hline K A T A K U N C I \\
\hline burung rangkong Sulawesi \\
densitas \\
jenis pakan
\end{tabular}

\begin{abstract}
A B S T R A K
Penelitian burung rangkong sulawesi sudah banyak dilakukan tetapi informasi mengenai densitas dan jenis pakannya masih sedikit. Tujuan penelitian ini adalah untuk mengetahui densitas dan jenis pakan burung rangkong sulawesi (Rhyticeros cassidix) di Cagar Alam Tangkoko Batuangus, Sulawesi Utara. Penelitian ini dilaksanakan pada bulan JuniAgustus 2014. Penelitian ini menggunakan metode garis transek (Transek Line) yang berjumlah 3 garis transek dengan panjang $2 \mathrm{~km}$ dan lebar transek 400 m, mulai dari ketinggian 11-208 m dpl. Hasil Penelitian ini menunjukan densitas tertinggi berada pada T2 dengan jumlah 47 ekor/ $\mathrm{km}^{2}$, dan terendah pada T1 31 ekor/ $\mathrm{km}^{2}$, dengan densitas rata-rata 37 ekor/ km². Hasil pengamatan mendapatkan 13 jenis makanan burung rangkong, yang meliputi 8 jenis buah dan 5 jenis serangga. Burung rangkong Sulawesi mengkonsumsi buah dan serangga, seperti buah beringin (Ficus benjamina), Asar mampuduar (Ficus virens), pohon dewan (Ficus altissima), Ficus caulocarpa, karet kerbau (Ficus elastic), kayu ara (Ficus tinctoria), pohon rao (Dracotomelon dao), kananga (Cananga odorata) dan jenis serangga seperti, kumbang tanduk (Oryctes rhinoceross), kumbang tanduk panjang (Batocera numitor), kumbang kelapa (Rhynchophorus vulneratus), kumbang tanduk rusa (Odontolabis bellicose), belalang (Valanga nigricornis).
\end{abstract}

K E Y W O R D S

Sulawesi hornbill density type of feed

\begin{abstract}
A B S T R A C T
There are many researches about Sulawesi Hornbill have been done but only few information about its density and type of food is available. The purpose of this study was to determine the density and type of food of Sulawesi hornbill (Rhyticeros cassidix) in Batuangus Tangkoko Nature Reserve, North Sulawesi. This study was conducted in June-August 2014. This study used three transect lines with a length of $2 \mathrm{~km}$, a width of 400 $\mathrm{m}$, and an altitude of 11-208 $\mathrm{m}$ above sea level. The results of this study showed the highest density was at T2 which is 47 head $/ \mathrm{km}^{2}$ and the lowest at T1 which is 31 individuals $/ \mathrm{km}^{2}$. The average density is 37 individuals $/ \mathrm{km}^{2}$. From the observation 13 kinds of food hornbill were found included eight kinds of fruit and five species of insects. Sulawesi hornbill eats fruits and insects, such as figs (Ficus benjamina), Asar mampuduar (Ficus virens), boards tree (Ficus altissima), Ficus caulocarpa, buffalo rubber (Ficus elastic), wood fig (Ficus tinctoria), tree rao (Dracotomelon dao), Kananga (Cananga odorata) and insects such as horn beetle (Oryctes rhinoceross), long-horn beetle (Batocera numitor), palm weevils (Rhynchophorus vulneratus), deer horn beetle (Odontolabis bellicose), grasshoppers (Valanga nigricornis).
\end{abstract}

TERSEDIA ONLINE

10 Februari 2015

*Corresponding author: Jurusan Biologi FMIPA UNSRAT, Jl. Kampus Unsrat, Manado, Indonesia 95115; Email address: brayenbleg@gmail.com Published by FMIPA UNSRAT (2015) 


\section{Pendahuluan}

Burung rangkong merupakan kelompok burung yang termasuk pada Famili bucerotidae. Ciri khasnya berupa paruh yang besar dengan struktur tambahan di bagian atasnya yang di sebut balung (casque) yang terdiri dari bahan tanduk yang keras dan kuat. Di Sulawesi burung ini dikenal masyarakat dengan beberapa nama seperti rangkong, julang, alow, dan burung taong. Ukuran tubuh berkisar antara 40-150 cm, dengan berat tubuh dapat mencapai 3,6 kg. Warna bulu pada bagian badan dan ekor di dominasi oleh warna hitam dan putih (Walting, 1983 dalam Rahma Fitry Nur et al., 2013).

Burung rangkong merupakan jenis burung pemakan buah (frugivory) yang paling besar di antara burung pemakan buah lainnya, buah yang di konsumsi oleh burung rangkong di kategorikan dalam buah yang kecil dalam jumlah yang banyak dan jenis buah yang memiliki batu (stone seeds), yaitu, jenis non ficus dan jenis ficus (Poonswad et al., 1998 dalam Mardiastuti et al., 2011).

Keberadaan burung rangkong penting bagi vegetasi hutan karena memiliki peran yang besar dalam meregenerasi hutan. Selain mamalia seperti kelelawar dan kera, penyebaran biji dapat di lakukan oleh burung-burung pemakan buah sehingga burung pemakan buah memiliki pengaruh yang besar dalam meregenerasi komunitaskomunitas tumbuhan di hutan (Herera, et al., 1994 dalam Partasasmita, 2008). Dibandingkan dengan kelelawar, kera dan burung pemakan buah lainnya, burung rangkong memiliki potensi yang lebih besar dalam penyebaran biji-bijian dihutan karena memiliki daya jelajah yang luas dari 39-55 km.

Ancaman yang utama bagi keberadaan burung rangkong adalah karena kehilangan habitat akibat dari penebangan pohon secara liar, pembukaan lahan pertanian, pembuatan jalan untuk keperluan pariwisata sehingga terjadinya frakmentasi hutan. Ancaman lainnya seperti perburuan untuk aksesoris, serta adat istiadat dalam masyarakat tertentu yang menggunakan burung rangkong dalam acara-acara kesenian atau lambang suatu suku. Saat ini status burung rangkong Sulawesi menurut CITES masuk Appendix II (Rasinta, 2010)

Penelitian tentang burung rangkong khususnya di Sulawesi Utara sudah banyak dilakukan. Penelitian yang pernah dilakukan oleh Suryadi (1994) mengenai burung rangkong Sulawesi difokuskan pada daerah jelajah, pergerakan harian, site fidelity (kesetiaan pada tempat) dan penyebarannya yang berlokasi di Cagar Alam Tangkoko Dua Sudara, informasi mengenai densitas dan jenis pakannya masih sedikit. Densitas (kerapatan atau kelimpahan) menunjukan besarnya populasi dalam satuan ruang. Umumnya dinyatakan sebagai jumlah individu atau biomasa persatuan luas atau volume. Densitas dalam studi kajian ekologi memiliki fungsi yang penting, karena berpengaruh terhadap populasi, komunitas dan ekosistem tidak hanya pada satu organisme saja tetapi dapat berpengaruh secara menyeluruh mencakup lingkungan, makanan, kompetisi, penyakit dan migrasi. Untuk itu penelitian ini perlu dilakukan dengan tujuan untuk mengetahui densitas atau kelimpahan dan jenis pakan burung rangkong di Cagar Alam Tangkoko Batuangus.

\section{Metode}

\subsection{Waktu dan Tempat Penelitian}

Penelitian ini dilaksanakan di Cagar Alam Tangkoko Batuangus selama bulan Juli-Agustus 2014. Lokasi penelitian hanya dilakukan pada satu habitat yaitu hutan primer.

\subsection{Pengambilan Data}

Pengambilan data untuk densitas burung rangkong dilakukan mengikuti garis transek sepanjang $2 \mathrm{~km}$ dan menyesuaikan dengan kondisi topografi serta kerapatan tegakan dilokasi pengamatan (Bismark, 2011). Pengambilan data dilakukan pada pagi-siang mulai dari jam 07.0013.00. Pencatatan penjumpaan dengan burung rangkong didasarkan pada suara dan penglihatan langsung dengan asumsi setiap individu yang ditemukan berbeda kemudian dilakukan pengamatan selama 10 menit. Pengambilan data meliputi jumlah jantan, betina dan anak-anak, serta aktivitas yang sedang dilakukan. Identifikasi jenis makanan dilakukan pada saat burung rangkong sedang beraktivitas makan dan juga hasil identifikasi pada kotoran burung rangkong.

\subsection{Teknik Pengambilan Sampel dan Analisis}

Perhitungan densitas burung rangkong pada setiap transek dilakukan dengan analisis sebagai berikut:

\section{Menghitung Rata-rata Burung Rangkong Pada Setiap Transek}

Rata-rata hitung atau disingkat mean. Penggunaan rata-rata hitung bersimbol ( $x^{-}$dibaca $X$ bar) perhitungan mean dibagi dua kelompok yaitu, perhitungan tunggal dan kelompok. Perhitungan yang digunakan pada analisis data ini adalah perhitungan tunggal dengan cara menunjukan semua nilai data dibagi banyaknya data (Riduwan dan Akdon, 2013). Untuk menghitung rata-rata:

$$
\mu=\frac{\sum_{i=1}^{N} x_{i}}{N} \quad \bar{x}=\frac{\sum_{i=1}^{n} x_{i}}{n}
$$




\section{Menghitung Densitas Burung Rangkong Pada Setiap Transek}

Analisis data untuk menghitung densitas burung rangkong digunakan rumus densitas, jumlah kontak dengan individu yang ditemukan dalam 10 hari pengamatan dibagi dengan panjang jalur pengamatan, lebar transek dikali 3 plot area. Untuk menghitung densitas:

$$
\begin{aligned}
D & =\frac{\sum \text { individu }}{\mathrm{L} \text { area pengamatan }} \mathrm{ekor} / \mathrm{km}^{2} \\
\text { atau } & =\frac{\sum \text { individu } / 10}{2 \mathrm{~km} \times 0,4 \mathrm{~km}} \mathrm{ekor} / \mathrm{km}^{2}
\end{aligned}
$$

\section{Hasil dan Pembahasan}

\subsection{Densitas Burung Rangkong Pada Setiap Transek}

Pengambilan data yang telah dilakukan di lokasi Cagar Alam Tangkoko Batuangus dengan menggunakan 3 transek dengan panjang $2 \mathrm{~km}$ dan lebar $400 \mathrm{~m}$ diperoleh, jumlah rata-rata individu pertransek, T1 (24.9 ekor/km²), T2 (37.7 ekor/km²), T3 (26.1 ekor $\left./ \mathrm{km}^{2}\right)$. Densitas tertinggi terdapat pada T2 $=47 \mathrm{~km}^{2}$ dan terendah yaitu di transek T1 $=31$ ekor $/ \mathrm{km}^{2}$, T3 = 33 ekor $/ \mathrm{km}^{2}$. Perbedaan densitas disetiap transek di pengaruhi oleh pohonpohon yang sedang berbuah. Jika dilihat dari jenis pakan yang ada di T1 dan T3 pada tabel lampiran 1, ketersediaan buah Ficus yang tidak terlalu banyak dan tidak dalam musim berbuah berpengaruh terhadap densitas burung rangkong yang berada pada T1 dan T3. Jenis buah yang ditemukan pada T1 yaitu Ficus benjamina dan Dracotomelon dao, pada T3 yaitu Ficus altissima dan Dracotomelon dao. Burung rangkong pada T1 dan T3 kebanyakan beraktivitas 1- 4 ekor atau berpasangan (jantan dan betina) dan jarang beraktivitas secara berkelompok dikarenakan ketersediaan buah yang terbatas. Menurut Fowler and Cohen, 1986; Novarino, 2008 dalam Fitry et al., 2013 berdasarkan jumlah individu, burung dapat dikelompokan ke dalam 4 kelas kelimpahan. Kategori umum 21-99 individu, tidak umum 5-20 individu, jarang 1 - 4 individu. Pada transek ini jumlah individu burung rangkong masuk dalam kategori umum 21-99 individu. Densitas burung rangkong pada setiap transek dapat dilihat pada tabel di bawah ini:

\begin{tabular}{|c|c|c|c|c|}
\hline \multirow{2}{*}{ No } & \multirow{2}{*}{ Hari } & \multicolumn{3}{|c|}{ Transek (Individu) } \\
\hline & & $\mathrm{T} 1$ & $\mathrm{~T} 2$ & $\mathrm{~T} 3$ \\
\hline 1 & ke 1 & 26 & 64 & 26 \\
\hline 2 & ke 2 & 23 & 64 & 24 \\
\hline 3 & ke 3 & 26 & 60 & 24 \\
\hline 4 & ke 4 & 27 & 42 & 23 \\
\hline 5 & ke 5 & 25 & 32 & 27 \\
\hline 6 & ke 6 & 27 & 23 & 26 \\
\hline 7 & ke 7 & 23 & 23 & 27 \\
\hline 8 & ke 8 & 25 & 23 & 28 \\
\hline 9 & ke 9 & 24 & 23 & 28 \\
\hline \multirow[t]{4}{*}{10} & ke 10 & 23 & 23 & 28 \\
\hline & Rata-rata & 24.9 & 37.7 & 26.1 \\
\hline & Densitas (ekor/ $\mathrm{km}^{2}$ ) & 31 & 47 & 33 \\
\hline & $\begin{array}{l}\text { Densitas rata-rata } \\
\left(\mathrm{ekor} / \mathrm{km}^{2}\right)\end{array}$ & & $37 \mathrm{~km}$ & \\
\hline
\end{tabular}

Tabel 1. Rata-rata Dan Densitas Burung Rangkong Pada Setiap Transek

Densitas burung rangkong pada T2 lebih tinggi dibandingkan T1 dan T3 hal ini disebabkan T2 lebih banyak tersedia sumber makanan, seperti buah $F$. benjamina, F. virens, F.altissima, F. caulocarpa, Ficus elastica, Ficus tinctoria, Dracontomelon dao, Cananga odorata dan beberapa jenis buah lainnya.

Pola distribusi yang berkelompok disebabkan karena adanya sumber makanan yang melimpah dan dalam musim berbuah pada transek ini. Menurut Fitry et al., (2013) pola distribusi yang mengelompok dicirikan dengan adanya puncak yang tertinggi. Puncak tertinggi kelompok burung rangkong terdapat pada T2 dengan jumlah 64 ekor.
Jadi densitas yang tinggi di T2 didorong oleh ketersediaannya pakan.

Menurut Kinnaird (1995) kepadatan pohon Ficus berpengaruh terhadap peningkatan densitas burung rangkong, karena burung rangkong melacak keberadaan Ficus dan jenis buah lainnya pada masa berbuah untuk, memenuhi kebutuhan makanannya. Menurut Wiens, (1992) dalam Kuswanda, (2009) ketersediaan pakan dalam suatu tipe habitat merupakan salah satu faktor utama bagi kehadiran populasi burung, akan tetapi beberapa hari kemudian jumlah populasi burung rangkong mengalami penurunan, diduga disebabkan oleh faktor cuaca ekstrim yaitu angin 
selatan yang bertiup kencang. Angin kencang juga meyebabkan buah-buah yang dikonsumsi burung rangkong termasuk Ficus Sp berkurang karena berjatuhan, sehingga burung rangkong menyebar untuk mencari sumber makanan dilokasi lainnya. Faktor lainnya yang mempengaruhi densitas burung rangkong adalah kompetisi antara hewan pemakan buah terutama kera hitam (Macaca nigra). Menurut Suryadi (1994) dalam Mardiastuti et al.,(1997) menemukan bahwa burung rangkong Sulawesi di Cagar Alam Tangkoko Batuangus lebih aktif pada sore hari karena pada pagi hari adanya kompetisi dengan kera hitam (Macaca nigra). Jika jumlah populasi kera hitam lebih banyak dibanding burung rangkong, burung rangkong akan pergi mencari makanan di lokasi lainnya, tetapi jika jumlah populasi burung rangkong lebih banyak, burung rangkong akan tetap berada dilokasi tersebut untuk makan.

\subsection{Jenis Pakan Burung Rangkong}

Pengambilan sampel dan identifikasi jenis makanan dilakukan pada saat burung rangkong sedang beraktivitas makan dan pada saat bersarang. Identifikasi juga dilakukan dengan mengidentifikasi kotoran burung rangkong.

Tabel 2. Jenis Pakan Burung Rangkong

\begin{tabular}{c|cc}
\hline \multirow{2}{*}{ No } & \multicolumn{2}{|c}{ Jenis pakan } \\
\cline { 2 - 3 } & Buah & Serangga \\
\hline 1 & Ficus benjamina & Oryctes rhinoceros \\
2 & Ficus virens & Batocera numitor \\
& Rhynchophorus \\
3 & Ficus altissima & vulneratus \\
4 & Ficus caulocarpa & Odontolabis bellicose \\
5 & Ficus elastica & Valanga nigricornis \\
6 & Ficus tinctoria & \\
7 & Dracontomelon celebium & \\
8 & Canaga odorata & \\
\hline Total & 8 jenis buah & 5 jenis serangga \\
\hline
\end{tabular}

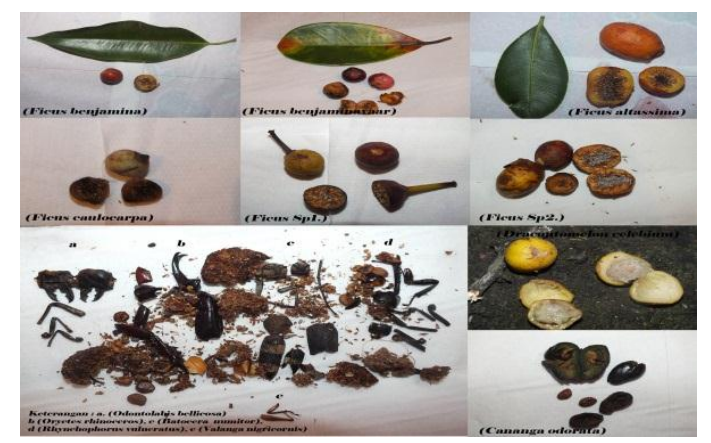

Gambar 1. Jenis Buah dan Serangga yang dikonsumsi Burung Rangkong

Hasil pengamatan mendapatkan 13 jenis makanan burung rangkong, yang meliputi 8 jenis buah dan 5 jenis serangga. Pada saat burung rangkong betina tidak berkembang biak, 80\% makanannya adalah buah Ficus (Gambar 7a) dan sisanya beberapa jenis buah lain seperti Cananga odorata, Drakotomelon dao. Sebelumnya pada masa berkembang biak konsumsi buah menurun menjadi $70 \%$ dan $30 \%$ jenis serangga seperti kumbang tanduk, kumbang kelapa dan belalang (Gambar 7b). Burung rangkong sendiri merupakan hewan yang masuk golongan omnivora atau hewan pemakan segala.

Ketersediaan sumber makanan yang melimpah serta keadaan hutan yang masih baik merupakan faktor yang mempengaruhi keberadaan burung rangkong dan kelimpahannya di Cagar Alam Tangkoko Batuangus. Hal ini dapat terlihat dari total densitas rata-rata pada setiap transek yang berjumlah 37 ekor $/ \mathrm{km}^{2}$. Peran ekologi burung rangkong sebagai Ornitokori pemancaran biji sangat penting bagi keberlanjutan ekosistem hutan di Cagar Alam Tangkoko Batuangus. Biji dari buah yang dikonsumsi burung rangkong yang tidak hancur ketika dicerna akan tumbuh dan berkembang dan menjadi individu baru. Hubungan timbal balik antara tumbuhan sebagai produsen dengan konsumen yaitu burung rangkong memiliki keterkaitan yang erat sehingga jika salah satunya mengalami kepunahan akan berpengaruh terhadap keberlanjutan ekosistem hutan Cagar Alam Tangkoko Batuangus.

\section{Kesimpulan}

1. Densitas burung rangkong di Tangkoko Batuangus tertinggi di T2= 47 ekor $/ \mathrm{km}^{2}$, terendah pada $\mathrm{T} 1=31 \mathrm{ekor} / \mathrm{km}^{2}$, dengan densitas rata-rata 37 ekor/ km².

2. Burung rangkong Sulawesi mengkonsumsi buah dan serangga, seperti buah beringin (Ficus benjamina), Asar mampuduar (Ficus virens), pohon dewan (Ficus altissima), Ficus caulocarpa, karet kerbau (Ficus elastic), kayu ara (Ficus tinctoria), pohon rao (Dracotomelon dao), kananga (Cananga odorata) dan jenis serangga seperti, kumbang tanduk (Oryctes rhinoceross), kumbang tanduk panjang (Batocera numitor), kumbang kelapa (Rhynchophorus vulneratus), kumbang tanduk rusa (Odontolabis bellicose), belalang (Valanga nigricornis).

\section{Daftar Pustaka}

Anonim, 2008. Buku Pertama Dokumen Rencana Aksi Konservasi Hutan Batang Toru Blok Barat.

Affandi, R.M \& Winarni, N. L, 2004. Prefensi Dan Interaksi Burung Rangkong Terhadap Ketersediaan Buah Ara (Ficus sp) Di Taman Nasional Bukit Barisan Selatan. Lampung. Jurusan Biologi FMIPA Universitas Lampung

Bismark, M. 2011. Prosedur Operasi Standar (SOP) Untuk Survei Keragaman Jenis Pada Kawasan Konservasi. Bogor. Pusat Penelitian dan Pengembangan Perubahan Iklim dan Kebijakan 
dan Penelitian dan Pengembangan Kehutanan Kementerian Kehutanan Republik Indonesia.

BKSDA Sulawesi Utara (Manado). 2009. Kegiatan Balai KSDA Sulut. [Jurnal]. Statistik Balai Konservasi Sumber Daya Alam Sulawesi Utara. Hal. 37.

Fitry, N.R. \& Novarino, W. Nurdin, J. 2013. Kelimpahan Dan Distribusi Burung Rangkong (FamiliBucerotidae) di Kawasan PT. Kencana Sawit Indonesia (KSI), Sumatera Barat. [Jurnal Biologika] Museum Zoologi, Jurusan Biologi, FMIPA Universitas Andalas. Vol. 2, No. 1, hal. 3031.

Hernandi. J, 2009. Bab 3 Ukuran Pemusatan Data.[Jurnal Statistika Dasar ]. Hal. 2

Kinnaird, M.F. O'Brien, T.G. Suryadi, S. 1995. Population Fluctuation In Sulawesi Red-Knobbed Hornbills Tracking fings In Space And Time. Wildlife Conservatio Snociety 185tha and Southern Blvd, Bronx, New York 10460, USA and Center for biodiversity and Conservation Studies, Faculty of Mathematics and sciences, University of Indonesia, depok 16424, Indonesia.

Koswara, S. 2014. Serangga Sebagai Bahan Pagan. Jakarta. Staf Pengajar IImu Dan Teknologi Pangan.
Mulyani, Y.A. Supriatna; A.A. Rahyuningsih; M. Novarino, W. 2005. Prosiding Seminar Ornitologi Indonesia. Perhimpunan Ornitologi Indonesia.

Mardiastuti, A. Rahma Salim, L.O. Mulyani, Y.A. 1997. Perilaku Makan Rangkong Sulawesi Pada Dua Jenis Ficus Di Suaka margasatwa Lambusango Buton. Jakarta. Laboratorium Ekologi Satwaliar Jurusan Konservasi Sumberdaya Hutan, Fakultas Kehutanan IPB.

Mutu, W. D. 2012. Penguasaan Tanah Di Dalam Kawasan Cagar Alam Gunung Duasudara Di Kota Bitung. [Skripsi]. Fakultas Hukum Universitas Hassanudin Makassar. Hal. 5.

Partasasmita, R. 2008. Ekologi Burung Pemakan Buah Dan Perannya sebagai Penyebar Biji.

Rasinta, U.D. 2010. Spesies Endemik Indonesia Dan Statusnya Menurut Cities. Pontianak. Universitas Tanjungpura Fakultas Pertanian IImu Tanah.

Riduwan. Akdon. 2013. Rumus Dan Data Dalam Analisis Statistika. Alfabeta. Jl. Gegerkalong Hilir 84 Bandung. Hal. 28

Saroyo. Siahaan, P. 2012. Biogeografi. Alfabeta. Jl. Gegerkalong Hilir 84 Bandung. 